\title{
Arachnoid Cyst and Psychosis: A Case Report
}

Dr. Navkiran Sooch Mahajan ${ }^{1 *}$, Dr. Ranjive Mahajan ${ }^{2}$, Dr. Jasleen Kaur Bhalla ${ }^{3}$

${ }^{1}$ Professor, ${ }^{2}$ Professor and Head, ${ }^{3}$ P.G. Resident, Department of Psychiatry, Dayanand Medical College and Hospital, Ludhiana, Punjab, India

DOI: $10.36347 /$ sjmcr.2021.v09i02.015

| Received: 09.02.2021 | Accepted: 20.02.2021 | Published: 25.02.2021

*Corresponding author: Navkiran Sooch Mahajan

Abstract

Case Report

The psychotic disturbances in a patient can either have an organic cause or a functional cause. One of the organic causes is the presence of any space occupying lesion in the brain like the Arachnoid cyst. We present the case report of a 15-year-old adolescent male who presented with insidious development of psychotic symptoms in the form of delusional ideas of referential and persecutory content, of varying intensity with second person auditory hallucinations, disturbance of sleep and behaviour in form aggression. He was admitted in our ward and his medical work up was within normal range including the neurological examination except for the neuroimaging studies that revealed an arachnoid cyst in the right temporal region with a marked mass effect on right temporal lobe. The neurosurgery consult suggested conservative management for the same and the patient was managed on antipsychotic (Risperidone) along with an anticonvulsant (Levetiracetam) during the hospital stay when his psychotic and aggressive symptoms started improving. Our case emphasises the importance of considering an organic cause like any space occupying lesion in the brain (arachnoid cyst in our case) for induction of psychopathological symptoms, even those of schizophrenia. It is difficult to be absolutely certain whether the lesion had influence on the patient's presenting psychiatric symptoms or not. However, due to the anatomical and neuropsychological changes, one cannot exclude the possibility that the lesion played a significant role in this case. This raises considerable problems when it comes to choosing a therapeutic strategy in such a patient like whether the surgical intervention for the arachnoid cyst would change the course, prognosis and the outcome of the psychiatric symptoms or whether the psychopharmacological intervention would be sufficient for a better outcome and quality of life of the patient.

Keywords: Arachnoid cyst, psychosis, right temporal lobe.

Copyright $(02021$ The Author(s): This is an open-access article distributed under the terms of the Creative Commons Attribution 4.0 International License (CC BY-NC 4.0) which permits unrestricted use, distribution, and reproduction in any medium for non-commercial use provided the original author and source are credited.

\section{INTRODUCTION}

Psychosis in a patient may be caused either by functional or organic conditions that cause changes in the perception and thinking [1]. Structural changes in the brain like space-occupying lesions or biochemical changes are among the many causes of psychosis that occur secondary to a general medical condition [2-6].

Arachnoid cysts are benign space-occupying lesions that contain CSF. They account for only $1 \%$ of all intracranial space-occupying lesions [7]. They occur quite commonly in males and occur about twice as often on the left side $(70 \%)$ [8, 9]. They can appear in any area of the brain or spinal cord, though they have been frequently observed in the Sylvian fissure (50\%) [8] and mid cranial fossa (34\%). These cysts are often diagnosed accidentally before adulthood (60-90\% prior to the age of 16). The clinical symptoms vary in patients depending on the location of the cyst and the age of the patient. During the childhood, hydrocephaly or cranial deformation is the most frequent manifestations, whereas in adolescents and adults, headaches and convulsive events are the most common [10]. Other clinical features include ataxia, ocular alterations, focal neurological signs, dizziness and altered memory $[8,11]$.

Although arachnoid cysts are mostly considered to be incidental lesions when found in patients with psychiatric disorders with no focal neurological signs [11], some studies still point to the existence of the causal relationship [11-21]. The finding of presence of an arachnoid cyst in a patient with psychosis raises diagnostic and therapeutic problems that are extremely significant from a clinical point of view $[11,12,15,18-20]$.

The aim of our case report is to highlight the cross-sectional diagnostic and therapeutic challenge to establish the causal relationship of the presence of intracranial arachnoid cyst in the patient of psychosis that would only be resolved over time with regular follow up of the patient. It also poses significant 
concerns regarding the course and outcome of the psychiatric disorder and raises relevance of therapeutic intervention (medical/surgical/ psychopharmacological) when both the conditions are co-existent in a patient.

\section{CASE Report}

We present the case of a 15-year-old adolescent male who was brought to the department of Psychiatry of Dayanand Medical College and Hospital, Ludhiana. The ethics committee permission has been sought for the same.

The patient was brought by the worried parents with the complaint of suspiciousness and altered behaviour of their son. According to them, since one and half years, when their son was studying in 7 th standard, he had undergone insidious onset of symptoms having a continuous but fluctuating course over time. The symptoms were in the form of paranoia, generalised distrustful attitude towards family and friends, disinterest and withdrawal from social activities like birthday parties and participation in sports events of school unlike his usual self. The parents noticed periods of prolonged vacant gaze, odd and inappropriate behaviour, with intermittent aggression, muttering to self and at times, self-laughing. The patient also reported having auditory hallucinations in the second person with referential, depreciatory and persecutory content. He had disturbed sleep, decreased self-hygiene and refusal to eat. The patient had falling academic grades and performance due to which parents had to drop him out from the school in 7 th standard. He also lost his contacts with friends. The family had sought to multiple religious/ spiritual faith healers but in the last 2 months, as the symptoms of the patient worsened and the condition deteriorated, psychiatric consult was taken. The patient was admitted in Psychiatry ward.

The general physical examination revealed an average weighted adolescent (BMI $24.3 \mathrm{~kg} / \mathrm{m} 2$ ) with no clinical signs of any abnormality. The neurological examination was also insignificant. During the mental state examination, the patient was seen scanning the interview room was alert, reactive and oriented to time and place. He looked perplexed. No formal thought disorder could be elicited. The thought content revealed preoccupations, delusions of reference and persecution and perceptual disturbance in the form of auditory hallucinations. The cognitive assessment was average and the Mini-Mental State Examination [22] was normal (29/30).

His prior medical history showed 3 episodes of febrile seizures during early developmental period for which no long term treatment was sought. He was eldest of his three siblings and his developmental milestones were attained within normal range. He had no history suggestive of substance abuse and his urine drug screen (done on the day of admission) was also negative. His family history had no significant seizure/ psychiatric disorders.

The blood investigations and urinalysis were normal on all parameters of laboratory work up. The awake EEG was also found to be normal. A 2D-MRI brain done during admission revealed the presence of an arachnoid cyst of $6.3 \times 5.0 \mathrm{~cm}$ at the level of the right temporal lobe, with a marked mass effect on the right temporal lobe. The neuropsychological examination showed IQ of 76 on MISIC (Malin's Intelligence Scale for Indian Children) (borderline intellectual ability). The neurology and neurosurgery consultation liaising was obtained which suggested conservative management of arachnoid cyst as it wasn't causing any focal neurological signs and symptoms in the patient and the risk of operating outweighed the advantage of surgery in this case as the temporal causal relationship could not be established between the cyst and psychosis.

The patient was started on antipsychotic therapy (Risperidone $1 \mathrm{mg}$ twice daily) for psychotic symptoms and anticonvulsant (levetiracetam) as prophylaxis in view of the potential risk of seizure. The psychotic symptoms started improving progressively during the hospital stay, with amelioration of the psychomotor agitation and remission of the auditory hallucinations. The patient is on regular follow up with us and is maintaining well on antipsychotics till now.

\section{DISCUSSION}

This patient's clinical picture is characterised by the insidious development of psychotic symptoms over one and half years in form of delusional ideas with a referential and persecutory content, second person auditory hallucinations and behavioural changes in the form of aggression. The patient did not present with the typical characteristics that distinguish whether the psychosis has a non-organic or an organic cause like autonomic instability in form of abnormal vital signs/ recent memory changes/ age more than 40years, ataxia, altered sensorium or focal neurological deficit although his 2D MRI brain showed arachnoid cyst. His urine tox panel was negative that ruled out any drug or substance induced psychopathology.

Hence, it is difficult to ascertain whether we are in the presence of an organic psychotic disorder or of a simple coincidence in which the arachnoid cyst is just an incidental finding as compared to the development of functional psychosis. Although the cyst seemed to be congenital, it did not cause any major symptoms earlier in life. Nevertheless, it may enlarge and interfere with adjacent neural structures or CSF circulation [7]. Association of psychiatric symptoms without any neurological manifestations, young age of onset, absence of family history for psychiatric disorders, evidence of compression of the right temporal lobe and neighbouring structures, and changes 
Navkiran Sooch Mahajan et al., Sch J Med Case Rep, Feb, 2021; 9(2): 174-177

in the neuropsychological tests are the factors that might suggest a causal relationship of arachnoid cyst to the psychiatric disorder. In our case, risperidone was chosen as it has shown good results in cases of psychosis associated with a general medical condition, including a case of psychosis associated with an arachnoid cyst [13, 23-26].

\section{CONCLUSION}

It is difficult to tell whether the lesion was innocent or not regarding this patient's overall psychiatric picture. The changes to the right temporal lobe with neuropsychological changes in our case leads to the conclusion that the possibility of the lesion in the etiopathogenesis of the psychotic symptoms cannot be excluded. As we do not have any prior evidence for the presence of the cyst, so the temporal relationship could not be established.

As per the current clinical practice, there are two aspects to the therapeutic approach in organic psychotic disorders i.e. controlling the symptoms and correcting the etiology. In this case of arachnoid cyst, the need for a surgical approach is neither clear nor uniform because intracranial hypertension or progressive hydrocephaly is usually the only situations where surgery is mandatory [7]. If neither of these indications is present and there are no focal neurological signs and symptoms, given both the morbidity associated with the surgery and the fact that this type of space occupying lesion can disappear spontaneously, the decision is generally conservative as was taken in our case too by neurology and neurosurgery departments. The evidence from literature suggests that although conservative management is the most common choice $[12,13,15,16]$, there have been cases in which surgical intervention was specifically adopted as a therapeutic approach to the psychotic symptoms $[11,14,18]$.

As the number of cases described in the literature increases, the psychotic symptoms in patients with this type of lesion cannot be unquestionably seen as just a coincidence [14, 18, 20, 21]. A more in-depth study of these types of cases is thus required in order to make it possible to optimise the therapeutic approach in cases involving the coexistence of arachnoid cysts in the brain and psychosis. The future prospects of the case aims to provide insight to the treating psychiatric team to look for and rule out organicity in all cases of psychosis and to establish the temporal relationship between the same so that the therapeutic interventions can be modified according to the individual case.

We would like to emphasise on the fact that along with regular follow up for psychiatric symptoms, patient should also be followed up for the change in size of the arachnoid cyst over period of time. The clinical symptoms should be addressed timely for any exacerbations or resurgence of either psychiatric symptoms or the neurological symptoms during follow up of such a case.

\section{REFERENCES}

1. Richards CF, Gurr DE. Psychosis. Emerg Med Clin North Am. 2000; 18:253-62.

2. Fricchione GL, Carbone L, Bennett WI. Psychotic disorder caused by a general medical condition, with delusions. Secondary "organic" delusional syndromes. Psychiatr Clin North Am. 1995; 18:363-78

3. Xavier M, Bento MS, Pereira DP, De Almeida JM: Acute psychotic disorder associated with vigabatrin. Acta Med Port. 2000; 13:111-4.

4. APA: Diagnostic and statistical manual of mental disorders: DSM-IV. 1994, Washington, D.C., American Psychiatric Association, xxvii,886p.-4th ed.

5. Corrêa BB, Xavier M, Guimarães J. Association of Huntington's disease and schizophrenia-like psychosis in a Huntington's disease pedigree. Clin Pract Epidemiol Ment Health. 2006; 2:1.

6. Xavier M, Correa B, Coromina M, Canas N, Guimaraes J. Sudden psychotic episode probably due to meningoencephalitis and Chlamydia pneumoniae acute infection. Clin Pract Epidemol Ment Health. 2005; 1:15-0.

7. Gosalakkal JA. Intracranial arachnoid cysts in children: a review of pathogenesis, clinical features, and management. Pediatr Neurol. 2002; 26:93-8.

8. Gelabert-Gonzalez M. Intracranial arachnoid cysts. Rev Neurol. 2004; 39:1161-6.

9. Wester K. Gender distribution and sidedness of middle fossa arachnoid cysts: a review of cases diagnosed with computed imaging. Neurosurgery. 1992; 31:940-4.

10. Gomez Escalonilla CI, Garcia Morales I, Galan Davila L, Gimenez-Torres MJ, Simon-Heras R, Valencia $\mathbf{J}$, et al. Intracranial arachnoid cysts. A study of a series of 35 cases. Rev Neurol. 2001; 33:305-11.

11. Kohn R, Lilly RB, Sokol MS, Malloy PF. Psychiatric presentations of intracranial cysts. J Neuropsychiatry Clin Neurosci. 1989; 1:60-6.

12. Blackshaw S, Bowen RC. A case of atypical psychosis associated with alexithymia and a left fronto-temporal lesion: possible correlations. Can J Psychiatry. 1987; 32:688-92.

13. Bahk WM, Pae CU, Chae JH, Jun TY, Kim KS. A case of brief psychosis associated with an arachnoid cyst. Psychiatry Clin Neurosci. 2002; 56:203-5.

14. Fontana M, Di Fonzo T, Aliquo C, Hadjichristos A. P.2.110 A case of schizophrenia-like psychosis in a patient with temporal arachnoid cyst. European Neuropsychopharmacology. 2003; 13:S328-8.

15. Krzyzowski J, Koziarski A, Wejroch A, Delimat L, Podgorski JK. A case of schizophrenia-like 
psychosis in a patient with arachnoid cyst. Neurol Neurochir Pol. 1998; 32:433-40.

16. Kuhnley EJ, White DH, Granoff AL Psychiatric presentation of an arachnoid cyst. J Clin Psychiatry. 1981, 42(4): 167-168.

17. Lanczik M, Fritze J, Classen W, Ihl R, Maurer K: Schizophrenia-like psychosis associated with an arachnoid cyst visualized by mapping of EEG and P300. Psychiatry Res. 1989; 29:421-3.

18. Colameco S, DiTomasso RA. Arachnoid cyst associated with psychological disturbance. J Med Soc N J. 1982; 79:209-10.

19. Cullum CM, Heaton RK, Harris MJ, Jeste DV. Neurobehavioral and neurodiagnostic aspects of late-onset psychosis. Arch Clin Neuropsychol. 1994; 9:371-82.

20. Vakis AF, Koutentakis DI, Karabetsos DA, Kalostos GN: Psychosis-like syndrome associated with intermittent intracranial hypertension caused by a large arachnoid cyst of the left temporal lobe. Br J Neurosurg. 2006; 20:156-9.
21. Wong CW, Ko SF, Wai YY: Arachnoid cyst of the lateral ventricle manifesting positional psychosis. Neurosurgery. 1993;32:841-3

22. Folstein MF, Folstein SE, McHugh PR: "Minimental state". A practical method for grading the cognitive state of patients for the clinician. J Psychiatr Res. 1975; 12:189-98.

23. Shenton ME, Dickey CC, Frumin M, McCarley RW. A review of MRI findings in schizophrenia. Schizophr Res. 2001; 49:1-52.

24. Furmaga KM, DeLeon OA, Sinha SB, Jobe TH, Gaviria M. Psychosis in medical conditions: response to risperidone. Gen Hosp Psychiatry. 1997; 19:223-8.

25. Frame DS, Kercher EE: Acute psychosis. Functional versus organic. Emerg Med Clin North Am. 1991; 9:123-36.

26. Price T. Neuropsychiatric aspects of brain tumours. Kaplan \& Sadock's comprehensive textbook of psychiatry. Edited by: Benjamin J. Sadock VAS. 2005, Philadelphia, Lippincott Williams \& Wilkins; 2005: 361-7. 